reviews. After merging similar questions, 104 were distributed for voting. From the 30 most popular uncertainties, the top 15 questions were prioritised in a facilitated workshop These include prevention and prediction of preterm birth, neonatal infection, lung damage, necrotising enterocolitis, preeclampsia, preterm premature rupture of the membranes, optimal neonatal feeding strategy, pain perception and management, a care package at neonatal discharge, emotional and practical support, attachment and bonding, and the best time for cord clamping.

Conclusions These priorities provide guidance to ensure that future research addresses questions that are important to service users and clinicians. Challenges for the priority setting partnership included maximising participation amongst people most affected by preterm birth, the breadth of the topic and securing input from an appropriate range of clinicians.

\section{PS-052a NEURODEVELOPMENTAL OUTCOME OF EXTREMELY PRETERM INFANTS AT 6.5 YEARS OF AGE; EXTREMELY PRETERM INFANTS STUDY IN SWEDEN (EXPRESS)}

${ }^{1} \mathrm{~F}$ Serenius, ${ }^{2} \mathrm{U}$ Ewald, ${ }^{3} \mathrm{~V}$ Fellman, ${ }^{4} \mathrm{M}$ Hafström, ${ }^{5} \mathrm{~K}$ Hellgren, ${ }^{6} \mathrm{~K}$ Källen, ${ }^{7} \mathrm{E}$ Lindberg, ${ }^{8} \mathrm{~K}$ Marsal, ${ }^{9} \mathrm{M}$ Norman, ${ }^{10} \mathrm{E}$ Olhager, ${ }^{11} \mathrm{~K}$ Stjernqvist, ${ }^{12} \mathrm{U}$ Åden, ${ }^{13} \mathrm{~A}$ Farooqi, ${ }^{2} \mathrm{~B}$ Strömberg. 'Women's and Children's Health, Uppsala University, Uppsala, Sweden; ${ }^{2}$ Pediatrics, Uppsala University, Uppsala, Sweden; ${ }^{3}$ Pediatrics, Lund University, Lund, Sweden; ${ }^{4}$ Pediatrics, Sahlgrenska University Hospital, Göteborg, Sweden; ${ }^{5}$ Ophthalmology, Karolinska University Hospital, Stockholm, Sweden; ${ }^{6}$ Centre for Reproductive Epidemiology, Lund University, Lund, Sweden; ${ }^{7}$ Pediatrics, Örebro University, Örebro, Sweden; ${ }^{8}$ Obstetrics Gynecology, Lund University, Lund, Sweden; ${ }^{9}$ Pediatrics, Karolinska University Hospital, Stockholm, Sweden; ${ }^{10}$ Pediatrics, Linköping University, Linköping, Sweden; ${ }^{11}$ Psychology, Lund University, Lund, Sweden; ${ }^{12}$ Pediatrics, Karolinska University Hospital, Stockholm, Sweden; ${ }^{13}$ Pediatrics, Umeå University, Umeå, Sweden

\subsection{6/archdischild-2014-307384.350}

Background Active perinatal care increases the survival of extremely preterm infants but there are concerns that improved survival might increase the rate of disabled survivors.

Objective To determine neurodevelopmental outcome at 6.5 years of age in extremely preterm children (EPT, $<27$ weeks) in a Swedish National cohort.

Design/methods Poulation-based prospective cohort of all EPT children born in Sweden from April 1, 2004, to March 31, 2007. Survivors were assessed and compared with a term-born control group. Of 707 live-born infants, 69\% survived to 6.5 years. Intellectual ability was measured with WISC- IV and results were related to the mean and SD of the controls. Clinical examination and parental questionnaires were used for diagnosis of cerebral palsy, hearing and vision impairments.

Results At a median age of 78 months, 445 of 494 eligible EPT children $(90 \%)$ were assed (59 by chart review). The rates of cerebral palsy, moderate visual impairment, blindness and deafness were $9.2 \%, 5.2 \%, 2.0 \%$ and $0.7 \%$, respectively vs $0.0 \%$, $0.5 \%, 0 \%$ and $0 \%$, respectively among 370 controls. 364 EPT children and 369 controls were formally tested with WISC-IV. Intellectual impairment $<-2$ SD but $>-3 \mathrm{SD}$, and $<-3 \mathrm{SD}$ was $9 \%$ and $19 \%$, respectively vs $1.9 \%$ and $0 \%$, respectively among controls. In 445 EPT children either formally assessed or by chart review, the rates of moderate and severe neurodevelopmental disabilities were $19 \%$ and $11 \%$, respectively compared with $2.4 \%$ and $0 \%$, respectively among control children.

Conclusion Disability rates are comparable to similar studies that report lower survival rates.

\section{Feeding Regimen}

\section{PS-053 VARIABILITY IN ADIPOKINES PROFILE OF NEWBORNS AND THEIR MOTHERS AFTER DHA SUPPLEMENTATION IN PREGNANCY}

${ }^{1}$ E Martín Alvarez, ${ }^{1} \mathrm{M}$ Peña-Caballero, ${ }^{1} \mathrm{JA}$ Hurtado-Suazo, ${ }^{2} \mathrm{~N}$ Kajarabille, ${ }^{3} \mathrm{~F}$ Lara-Villoslada, ${ }^{2} \mathrm{JJ}$ Ochoa. ${ }^{1}$ Paediatric, Hospital Universitario Virgen de Las Nieves, Granada, Spain; ${ }^{2}$ Nutrition, Institute of Nutrition and Food Technology "José Mataix", Granada, Spain, ${ }^{3}$ R\&D Department, Lactalis Puleva, Granada, Spain

\subsection{6/archdischild-2014-307384.351}

Background/aims Most studies of DHA supplementation during pregnancy and infant development are focused on visual and neural development. However, scarce information is available about the influence of DHA supplementation on adipokines expression, which are related to adipose tissue metabolism and obesity.

Aim Evaluate the effect of DHA supplemented dairy drink consumption during pregnancy and breastfeeding on the expression of several adipokines in mothers (pregnancy, delivery and breastfeeding) and their newborns (birth and 2.5 months of age).

Methods 60 women were randomly assigned to two intervention groups: A) Control Group ( $\mathrm{n}=30)$; B) Supplemented Group ( $\mathrm{n}=30)$ : The women took 2 glasses/day of the supplemented drink (400 mg DHA/day). Dietary intervention began in week 28th of pregnancy and concluded when breastfeeding stopped. Samples of blood were obtained from: the mothers, the umbilical vein and artery; the newborn at 2.5 months postpartum. Adiponectin, resistin, leptin and active PAI-1 plasma levels were determined using a panel from Luminex xMAP technology. Results Adiponectin was higher in the supplemented group in umbilical cord artery, whereas active-PAI showed a lower value in this group, although we observed an increase in mother's blood during delivery. Resistin did not show any difference. Leptin was higher in the supplemented group in umbilical cord.

Conclusion The most noteworthy result is the effect of DHA supplementation in umbilical cord artery adipokine levels, increasing the adiponectin and decreasing the active PAI-1. In addition, active PAI-1 increases in mothers during delivery. It is also interesting the increase in the supplemented group of leptin.

\section{\begin{tabular}{|l|l}
\hline PS-054 & VSL\#3 SUPPLEMENTATION TO MOTHERS DURING
\end{tabular} PREGNANCY AND BREAST FEEDING IMPROVES COLICS AND REGURGITATION IN NEWBORNS, PERHAPS BY TGF-B MODULATION}

${ }^{1} \mathrm{ME}$ Baldassarre, ${ }^{2} \mathrm{P}$ Mastromarino, ${ }^{3} \mathrm{~A}$ Miccheli, ${ }^{4} \mathrm{M}$ Fanelli, ${ }^{1} \mathrm{~A}$ Dileone, ${ }^{1} \mathrm{P}$ Drimaco, ${ }^{1} \mathrm{~N}$ Laforgia. 'Department of "Scienze Biomediche ed Oncologia Umana"- Neonatology and NICU Section, University of Bari, Bari, Italy; ${ }^{2}$ Department of Public Health and Infectious Diseases, University "La Sapienza", Rome, Italy; ${ }^{3}$ Department of Chemistry, University "La Sapienza", Rome, Italy; ${ }^{4}$ Department of Internal Medicine and Public Health-Section of Nuclear Medicine-Medical Statistics, University of Bari, Bari, Italy

\subsection{6/archdischild-2014-307384.352}

Aim To evaluate the influence of maternal supplementation with VSL\#3 on digestive events in newborns and cytokines levels in colostrum and mature breast milk.

Methods This pilot double-blind, randomised, placebo-controlled clinical trial (clinicaltrials.gov: NCT01367470) enrolled four weeks before expected delivery healthy pregnant women that received daily oral VSL\#3 (PTM) or placebo (CM) supplementation until four weeks after delivery. In milk samples we 